described by Sharpstone et al. (1968) did not have a diuresis until between three and four weeks after the onset of anuria. Histological examination in Case 2 showed generalized glomerular involvement of only moderate severity, which we feel will ultimately resolve. Case 3 , however, had severe damage of about two-thirds of the glomeruli, and though he survived the acute illness he may eventually develop chronic renal insufficiency. This has been reported in as many as $30 \%$ of patients who survive the acute illness (Gianantonio et al., 1968). Detailed renal histology, in patients treated adequately with heparin, has previously been reported in only two cases; one had widespread glomerular damage and thrombotic lesions (Hitzig, 1964), and the other had essentially normal glomeruli (Piel and Phibbs, 1966).

The reports of heparin therapy are too few for its usefulness to be assessed, and a controlled trial planned to take into account the variable severity of the disease is required. Examination of renal histology in our Cases 2 and 3, however, suggests that heparin therapy was beneficial, for, despite widespread glomerular damage, only occasional thrombotic lesions were seen. These findings suggest that severe renal damage had occurred before the institution of heparin therapy, but that further intrarenal thrombosis was prevented by heparin, allowing removal of existing thrombi by the normal fibrinolytic process. We agree with Dacie (1957) that the further use of heparin in treatment of the haemolytic-uraemic syndrome is warranted, but we believe that more information about its effects could be obtained if post-treatment evaluation included an examination of the renal histology in survivors as well as those who succumb.

We are grateful to Dr. J. G. Dathan, Dr. R. D. C. Johnstone, and Dr. R. D. G. Creery for kindly referring these patients; to Dr. R. H. R. White, under whose care they were admitted, for his encouragement and advice; to Dr. J. Stuart and the staff of the naematology department for their help; and to Dr. A. H. Cameron and the staff of the pathology department for help with the interpretation and preparation of the histological material.

\section{REFERENCES}

Boen, S. T., (1966). In European Dialysis and Transplant Association: Proceedings of the 2nd Conference on Renal Failure and Replacement of Renal Function, edited by D. N. S. Kerr, p. 75. Amsterdam, Excerpta Medica.

Brain, M. C., Baker, L. R. I., McBride, J. A., and Rubenberg, M. (1967). Quarterly fournal of Medicine, 36, 608 .

Dacie, J. V., (1967). The Haemolytic Anaemias, 2nd ed., p. 875. London, Churchill.

Desmit, E. M., Hart, H. C., Helleman, P. W., and Tiddens, H. A. W. M. (1966). In European Dialysis and Transplant Association: Proceedings of the 2nd Conference on Renal Failure and Replacement of Renal Function, edited by D. N. S. Kerr, p. 68. Amsterdam, Excerpta Medica.

Gasser, C., Gautier, E., Steck, A., Siebermann, R. E., and Oechslin, R., (1955). Schweizerische medizinische Wochenschrift, 85, 905.

Gianantonio, C., Vitacco, M., Mendilaharzu, F., Rutty, A., and Mendilaharzu, J. (1964), fournal of Pediatrics, 64, 478 .

Gianantonio, C., Vitacco, M., and Mendilaharzu, F. (1967). In Proceedings of Third International Congress of Nephrology, edited by L. E. Becker, Vol. 3, p. 24. Basel, Karger.

Gianantonio, C. A., Vitacco, M., Mendilaharzu, F., and Gallo, G. (1968). Fournal of Pediatrics, 72, 757.

Gilchrist, G. S., and Liebermann, E. (1969). Lancet, 2, 1069.

Gilchrist, G. S., Liebermann, E., Ekert, H., Fine, R. N., and Grushkin, C. (1969). Lancet, 1, 1123 .

Habib, R., Mathieu, H., and Royer, P. (1967). Nephron, 4, 139.

Hitzig, W. H. (1964). Helvetica Paediatrica Acta, 19, 213.

Katz, J., Lurie, A., and Kaplan, B. (1969). Lancet, 2, 700.

Kibel, M. A., and Barnard, P. J. (1964). Lancet, 2, 259

Künzer, W., and Aalam, F. (1964). Lancet, 1, 1106.

Liebermann, E., Heuser, E., Donnell, G. N., Landing, B. H., and Hammond, G. D. (1966). New England fournal of Medicine, 275, 227.

Merskey, C., Kleiner, G. J., and Johnston, A. J. (1966). Blood, 28, 1.

Monnens, L., and Schretlen, E. (1968). Lancet, 2, 735.

Piel, C. F., and Phibbs, R. H. (1966). Pediatric Clinics of North America, 13, 295.

Rodríguez-Erdmann, F. (1965). New England fournal of Medicine, 273,

Sharpstone, P., Evans, R. G., O'Shea, M., Alexander, L., and Lee, H. A. (1968). Archives of Disease in Childhood, 43, 711.

Shinton, N. K., Galpine, J. F., Kendall, A. C., and Williams, H. P. (1964). Archives of Disease in Childhood, 39, 455.

Verstraete, M., Vermylen, C., Vermylen, J., and Vandenbroucke, J. (1965). American fournal of Medicine, 38, 899.

\title{
Routine Induction of Labour by Amniotomy and Simultaneous Syntocinon (Synthetic Oxytocin) Infusion
}

\author{
MICHAEL E. PAWSON, ${ }^{*}$ M.B., B.S., M.R.C.O.G. ; STANLEY C. SIMMONS,† F.R.C.s., M.R.C.o.G.
}

\begin{abstract}
Summary: Of 2,272 deliveries between 1 October, 1967 and 31 December, 1968290 were induced by simultaneous intravenous Syntocinon (synthetic oxytocin) at amniotomy. The hazards of induction of labour are greatly reduced when this method is used routinely. Only 4 of the 13 caesarean sections were thought to be due to failure of method. Within 12 hours 221 patients were delivered, and this short induction-delivery interval resulted in an extremely low maternal and fetal morbidity. It is believed that with proper safeguards and in the light of present knowledge this is the method of choice.
\end{abstract}

\section{Introduction}

Induction of labour by amniotomy and simultaneous Syntocinon (synthetic oxytocin) infusion shortens the induction delivery interval and appreciably reduces the incidence of failure. This, in turn, lowers the incidence of infection (both fetal and maternal) and caesarean section.

A preliminary trial of this method as a routine indicated

- Registrar.

tConsultant.

Windsor and Slough Obstetric Unit, Upton Hospital, Slough, Bucks. that hazards of induction could be greatly reduced (Garud and Simmons, 1968). The results from 1 October 1967 to the end of 1968 confirm our original findings, and for that reason they are presented. The total experience is derived from over 950 cases.

\section{Method}

Labour was induced in $290(12.7 \%)$ of 2,272 deliveries. The indications are shown in Table I. After routine preparation and premedication with pethidine, forewater rupture was performed at 9 a.m. Simultaneously, intravenous Syntocinon

TABLE I.-Indications for Induction

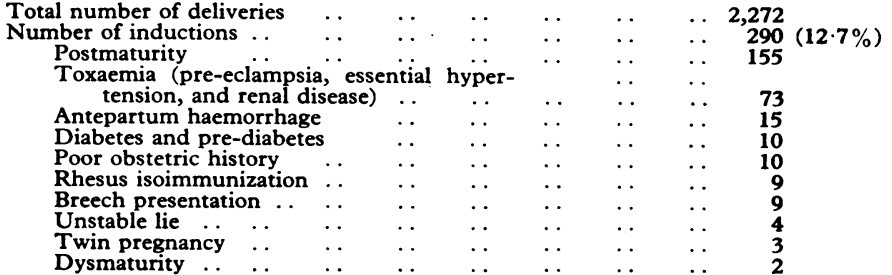


0.5 unit in $500 \mathrm{ml}$. of $5 \%$ dextrose at 20 drops per minute was set up. This constitutes an intravenous infusion of 1.32 milliunits of Syntocinon per minute. The rate was increased every 15 minutes from 20 to a maximum of 60 drops per minute and the strength from 0.5 to 5 units per $500 \mathrm{ml}$. It will be seen (Fig. 1) that as the concentration is increased the total

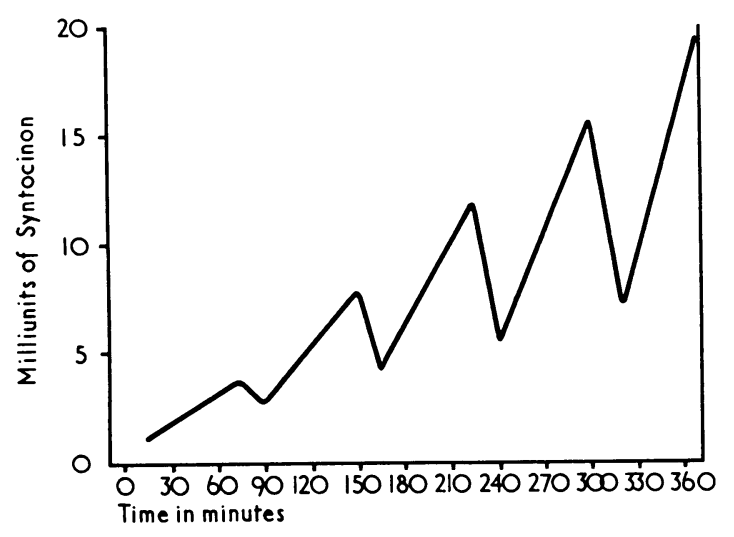

Frg. 1.-Rate of Syntocinon infusion.

dosage is reduced for a variable period. A more accurate method of administration can be achieved with an infusion pump, which has now been introduced into this unit.

If the cervix was "unfavourable," or the presenting part high, Syntocinon was given intravenously for a variable time before the membranes were ruptured (provided that disproportion had been excluded). If labour was not established by the evening the infusion was discontinued, to allow a night's rest, and restarted the following morning. Supervision of labour during the first 15 to 30 minutes was by the medical staff and subsequently by the staff midwife, sister, and a pupil midwife.

The maternal pulse, blood pressure, fetal heart rate, and frequency and duration of contractions were recorded at 15minute intervals. The temperature was recorded four-hourly.

\section{Results}

The results are summarized in Tables II-V and in Fig. 2. Thirteen (4.8\%) out of 290 patients failed to deliver by the vaginal route (Table II). Four deliveries were regarded as failure of the method of induction; all four were prolonged labours, one associated with a face presentation. The indications for a caesarean section are summarized in Table III. The caesarean section rate was $4.8 \%$, compared with an overall hospital rate of $6.2 \%$. The corrected rate, however, was $1.4 \%$, and these cases are analysed more closely below. There were 22 forceps deliveries $(7.6 \%)$, compared with the overall hospital rate of $8.1 \%$. There were no maternal deaths. There was no uterine rupture. Infection was minimal.

Puerperal pyrexia (a temperature of $99 \cdot 4^{\circ} \mathrm{F}$. $\left(37 \cdot 4^{\circ} \mathrm{C}\right.$.) on two occasions or $100.4^{\circ} \mathrm{F}$. $\left(38^{\circ} \mathrm{C}\right.$.) on one occasion) was present in 13 cases (Table IV). Only five resulted from genital tract infection. In addition to these cases one patient was readmitted with bilateral pyosalpinx eight weeks after delivery. There were two neonatal deaths in this series-one associated with eclampsia and accidental haemorrhage at 28 weeks and one at 32 weeks from accidental haemorrhage.

The Apgar score was recorded in 260 cases; in the remainder only the general condition of the baby was recorded. (Table V).

Fetal distress was defined as the appearance of meconium in the liquor, a fetal heart rate below 120 or above 160 , or the pH below 7.2 on fetal blood sampling (Table VI). None of the 41 "distressed" babies was lost. In nine the findings
TABLE II.-Results of Induction of Labour

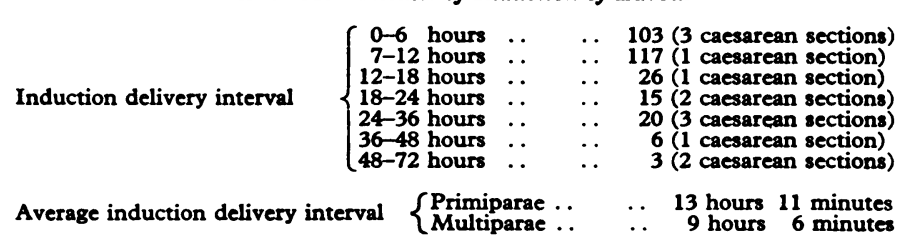

TABLE III.-Indications for Caesarean Section

Fetal distress .

Failed induction

Face presentation

Transverse lie in labou

Fulminating pre-eclampsia

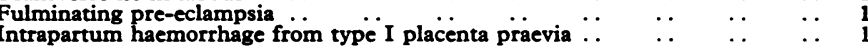

TABLB IV.-Puerperal Pyrexia

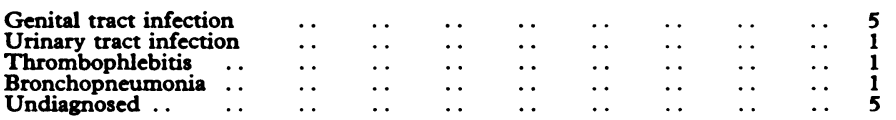

TABLE V.-Apgar Score in 260 Cases

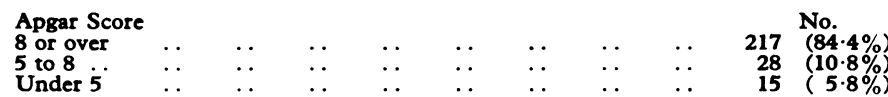

5 to 8 .

TABLE VI

Fetal distress

Meconium

Bradycardia

Tachycardia

Meconiuty $\ldots$

were considered significant enough to indicate fetal blood sampling, and in the remainder the finding was either not considered significant or the baby was delivered before sampling was carried out. Of the nine sampled babies only one had a $p H$ of 7.25 or less, and this was in the second stage; it was delivered soon after and the Apgar was 9. The Apgar score at birth in the remaining eight sampled babies was 8 or over at birth. Of the 32 with "distress" not sampled six had Apgar scores below 7 at birth, but all were normal within 10 minutes. Three of the six followed caesarean section. One had signs of fetal distress just before delivery.

An increased incidence of post-partum haemorrhage (500 $\mathrm{ml}$. or more) was noted in 24 cases, an incidence of $8.3 \%$, compared with an overall rate of $3.4 \%$ during the same period. This occurred despite the continuation of Syntocinon for one hour after delivery and the use of intramuscular Syntometrine (synthetic oxytocin and ergometrine) with the birth of the anterior shoulder. (The placenta was delivered by controlled cord traction after signs of placental separation had been observed.)

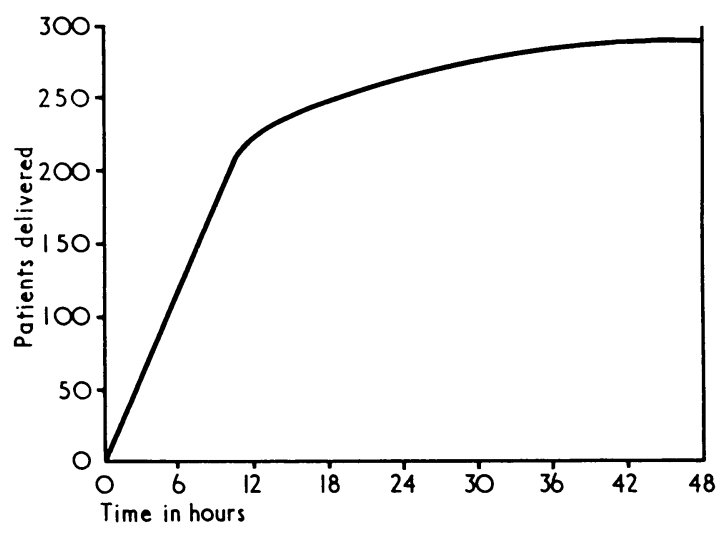

FIG. 2.-Time of delivery. 


\section{Failed Induction}

Case 1.-A primipara aged 23 booked for delivery at a nursinghome but transferred because of a mild pre-eclampsia at term. Because the head was high she was given a Syntocinon drip for two days and amniotomy was then performed. Labour never progressed very satisfactorily despite giving 5 units of Syntocinon in $500 \mathrm{ml}$. of dextrose at 60 drops a minute. Forty-eight hours after amniotomy the cervix was still only $5 \mathrm{~cm}$. dilated and caesarean section was performed. The baby weighed $8 \mathrm{lb} .9 \mathrm{oz}$. $(3,885 \mathrm{~g}$.).

Case 2.-A para-2 aged 36 whose first baby had been delivered by caesarean section for placenta praevia was induced for postmaturity, but because of the uterine scar no more than 1 unit of Syntocinon was given in $500 \mathrm{ml}$. of dextrose. She was not in established labour 48 hours after amniotomy, so a repeat caesarean section was performed. The baby weighed $8 \mathrm{lb} .9 \mathrm{oz}$. (3,885 g.).

Case 3.-Induction was performed for post-maturity and labour became established quickly. A left mentolateral position was diagnosed, however, and the cervix failed to dilate beyond $6 \mathrm{~cm}$. Caesarean section was performed two hours after amniotomy. The baby weighed $7 \mathrm{lb} .12 \mathrm{oz}$. $(3,515 \mathrm{~g}$.).

Case 4.-Induction was performed on an elderly primipara at term when slight staining of the liquor was observed at amnioscopy. Despite reaching a concentration of 10 units of Syntocinon at 60 drops per minute, the cervix failed to dilate beyond $5 \mathrm{~cm}$., so caesarean section was performed after 48 hours. The baby weighed 10 lb. 6 oz. (4,705 g.).

\section{Discussion}

The need for indications for induction of labour is well known and, particularly in the case of post-maturity, was emphasized after the perinatal mortality survey (Butler and Bonham, 1963). Artificial rupture of the membranes is associated with numerous hazards-in particular, intrauterine infection and failure leading to caesarean section, frequently in the presence of established infection. Sepsis and paralytic ileus account for $17.9 \%$ of deaths following caesarean section (Arthure et al. 1969). There are two possible solutions to the problem of induction failure: (1) to reduce the induction rate by a more selective approach, and (2) to make induction of labour more rapid and effective. Investigations such as urinary oestrogen assay, Nile blue staining of amniotic fluid to determine the duration of pregnancy, amnioscopy for meconium, and monitoring the fetus in labour by fetal blood sampling and cardiotocography have all in their turn reduced the tendency to "statistical" induction. These methods are being used with increasing frequency in this department (Garud, May, and Simmons, 1969), but when the decision to induce has been taken an effective outcome depends on a positive approach and a determined method.

Despite the use of the intravenous infusion of Syntocinon 24 or 48 hours after rupture of the membranes and the use of prophylactic antibiotics, the failure rate has persisted in the region of 10\% (Brudenell, 1965; Pinkerton, 1968) while the use of prophylactic antibiotics is not only uncertain in effect but potentially dangerous in hospital practice. Though the value of Syntocinon following amniotomy as early as 12 hours after rupture of the membranes has been pointed out (Turnbull and Anderson, 1968), its use routinely and simultaneously with amniotomy was suggested (Bradford and Gordon, 1968; Garud and Simmons, 1968). Acceptance of this method as a routine will naturally be hesitant. There are numerous theoretical disadvantages-uterine rupture following hypersensitivity, fetal asphyxia, interference with normal uterine action, additional work-load, and patients' discomfort-but in practice and with the technique advised these do not occur; furthermore, the failure and infection rates are greatly reduced and associated with a reduction in fetal and maternal morbidity and mortality. It must be emphasized, however, that suspected disproportion constitutes an absolute contraindication. Previous caesarean section and grand multiparity have been regarded as relative contraindications, but in this series labour was induced in such patients with a small dose of Syntocinon and special care. Fetal asphyxia was not seen.

A questionary to all patients after inductions confirmed that patients' discomfort is not a significant factor. As we have previously pointed out, the additional work-load, though requiring organization, once established is readily accepted by medical and nursing staff. The knowledge that most patients so induced will be delivered within 12 hours of induction is a considerable advantage, and the effect on morale is substantial. The incidence of post-partum haemorrhage conflicts with our previous report and has been noted elsewhere. As a result of these findings the drip is now run for two hours post-partum.

In the light of present knowledge both the medical and the nursing staff of this hospital are convinced that this method is the best available for induction of labour and would be loath to return to any alternative. Nevertheless, it is to be emphasized that it is merely part of the whole approach to induction of labour, of which the selection of cases is at least as important. It is recognized that there are potential risks with Syntocinon and that adequate safeguards must be taken if it is to be used in this way.

We wish to thank Mr. C. T. F. Ealand for permission to include patients under his care; the superintendent and deputy superintendent midwives, Miss Helen Broome and Miss Olive Miller; and their staff for co-operation; also Miss S. Feedam for her help with the graphs.

\section{REFERENCES}

Arthure, H., et al. (1969). Reports on Public Health and Medical Subjects, No. 119. London, H.M.S.O.

Bradford, W. P., and Gordon, G. (1968), fournal of Obstetrics and Gynaecology of the British Commonwealth, 75, 698.

Brudenell, J. M. (1965). Proceedings of the Royal Society of Medicine, 58,308 .

Butler, N. R., and Bonham, D. G. (1963). Perinatal Mortality. The First Report of the 1958 British Perinatal Mortality Survey, Edinburgh, Livingstone.

Garud, M. A., May, D. P. L., and Simmons, S. C. (1969). British Medical fournal, 1, 346.

Garud, M., and Simmons, S. C. (1968), Journal of Obstetrics and Gynaecology of the British Commonwealth, 75, 702.

Pinkerton, J. H. M. (1968). British Medical fournal, 3, 369.

Turnbull, A. C., and Anderson, A. B. M. (1968). Fournal of Obstetrics and Gynaecology of the British Commonwealth, 75, 24. 